\title{
Spontaneous Determinants of Protein Aging Mini Review
}

Contents:

\author{
Dyakin ${ }^{1}$ V.V. Uversky ${ }^{2}$, V.N.
}

\begin{abstract}
Introduction

Proteins Aging: Spontaneous, Age-dependent PTMs

Racemization

Glycation
\end{abstract}

Conclusion

Afterword

\author{
Abbreviations \\ Advanced glycation endproducts (AGPs). \\ Amino acids (AAs). \\ Deoxyribonucleic acid (DNA). \\ Heat shock proteins (HSPs). \\ Local minimums of Gibbs free energy $\left(\mathrm{E}^{\mathrm{min}}\right)$. \\ Post-translational modification (PTM). \\ Unfolded protein response (UPR)
}

Key words: protein aging, spontaneous post-translational modification, racemization, glycation, glycosylation.

\section{There is no conflict of interest.}

\section{Affiliation}

1. Victor Vasilyevich Dyakin (Correspondence author): The Nathan S. Kline Institute for Psychiatric Research (NKI). Address: 140 Old Orangeburg Road, Bldg. 35. Orangeburg. NY. 10962-1167. USA. Bld.35. Phone: 845-548-96-94. Fax: (845) 398-5510. E-mail: dyakin@nki.rfmh.org (primary) dyakin@NKI.RFMH.ORG; Head of Virtu-al Reality Perception Lab. (VRPL)

2. Vladimir N. Uversky: Department of Molecular Medicine and USF Health Byrd Alzheimer's Center and Research Institute, Morsani College of Medicine, University of South Florida, Tampa, FL 33612, USA. E-mail”vuversky@usf.edu

\section{Acknowledgment}

We gratefully thank Abel Lajtha, Alexander G. Dadali, and Matthew Collins for productive discussions and corrections. 


\begin{abstract}
The universal chirality is the commonly accepted view of nature. Biological chirality is the distinct part of the more general phenomena. Following this view, all living organisms are characterized by the non-equilibrium state of their molecular constituents. From the thermodynamic perspective, the non-equilibrium state of biomolecular ensemble holds inevitable consequences being the substrate of spontaneous reactions directed to equilibrium (not associated with life) state.

At the protein level, spontaneous biological reactions represent the natural part of proteins' post-translational modifications (PTMs). The essential contribution to the origin and maintenance of the non-equilibrium state belongs to prevalent bio-molecular chirality. Correspondently, spontaneous PTMs such as racemization and glycation, working against life-supporting prevalent chirality, are known as the significant determinants of protein misfolding, dysfunctions, and aggregation. Accumulation of aberrant protein during life-span allows consideration of time-dependent spontaneous racemization and glycation as protein aging. Spontaneous PTMs of proteins is occurring in the interaction with other forms of enzymatic and non-enzymatic PTMs.

In this review, we are considering the contribution of spontaneous racemization and nonenzymatic glycosylation to protein aging.
\end{abstract}




\section{Introduction}

The prevalent molecular chirality plays a causal role in neuronal polarity and motility, which in turn, are the cellular determinant of the brain bilaterality and the asymmetry of perceptual, cognitive, and behavioral functions $[1,2,3]$. Generally speaking, brain-body mediated interaction of the internal bio-molecular chirality with the external environment's chiral factor occurs due to the hierarchical chain of chirality transfer [1] associated with the hierarchical organization of living systems [4]. Aging, identified as a time-dependent process leading to the loss of biological functions and the onset of agerelated diseases, should be explored across the matrix of hierarchical domains. The multi-modal determinants of lifetime involve complex bio-chiral events, most of which are not entirely understood. The hierarchical relationship of molecular, phenotypic, and functional aging domains recently gains attention [5]. The development and longevity of organisms are linked through adaptation to the environment [6,7]. Such evolutionary adaptation occurred through the hierarchical levels of biological complexity: molecular [10], cellular, organ, and organism [8,9].

At the organism level, aging is characterized by the progressive loss of physiological and perceptual functions and terminated by death. A species-specific lifetime duration makes it plausible that the aging of molecular constituencies, cells, and the organism is programmed in genes [11] and mediated by the epigenetic impact [12].

At the molecular level, aging is influenced by the transcriptional and post-transcriptional regulatory mechanisms involving crosstalk of DNA and protein pathways $[13,14,15]$. In all animal species, the biological clock of molecular aging is associated with epigenetic changes involving DNA methylation and post-translational modification (PTM) of proteins [16]. Recent development reveals that protein turnover and pathological protein aging are mediated by the set of enzymatic and spontaneous PTMs (see Fig. 1) [14, 17].

\section{Proteins Aging: Spontaneous Age-dependent PTMs}


Various theories of molecular aging have been proposed. As the most abundant and structurally diverse components, proteins represent a suitable platform for analyzing age-associated molecular mechanisms. Most studied mechanisms are linked to spontaneous non-enzymatic PTMs [18]* such as oxidation [19], nitration [20], racemization [14] and glycation [21]. Non-enzymatic PTMs are recognized as an integral part of cellular metabolism [22]. In the network of PTMs, seemingly distinct biological reactions such as phosphorylation and racemization [13] or racemization, glycation, and glycosylation, [19] share many common chemical, metabolic and thermodynamic attributes. Spontaneous racemization and accumulation of advanced glycation end-products (AGPs) have been most intensively studied concerning protein aging, aggregation, and dysfunctions in the fields of neuroscience [1-3] and forensic applications [15]. In our review, we are considering the contribution of spontaneous racemization [13, $23]$ and non-enzymatic glycosylation [24 - 26] to protein aging.

\section{Racemization}

The spontaneous transformation of L-AAs to D-AAs (mirror images of each other) in peptides and proteins is associated with the dramatic changes in the three-dimensional (3-D) orientation of the molecular orbitals. Therefore, racemization can significantly alter not only primary, but secondary and even higher-order protein structures, thereby leading to alterations in corresponding cellular functions (the example of an exception is leucine) [27]. The racemization may also play a role in protein proteolytic stability as L-enzymes (including proteases) would not work on D-substrates. Since racemization is a time-dependent phenomenon, it can be used to determine the relative age and turnover rates of longlived proteins [20]). Furthermore, in some diseases (e.g., musculoskeletal diseases [20] and likely in the normal aging, turnover rates can be altered, generating pathologically racemized proteins. Due to the

\footnotetext{
* The non-enzymatic and enzymatic reactions obey the same thermodynamic principles, As a result, every enzymatic reaction can occur in principle also non-enzymatically [18].
} 
advances in chiral proteomics, it has become known that protein misfolding and malfunction, associated with the snowballing and accelerated accumulation of aberrant proteins, correlate with the irreversibility of age-related and disease pathology [28, 29].

\section{Glycation}

Glycation has been studied for over 100 years. However, its importance in biology, the science of aging, medicine, food and nutrition, pharmacology and toxicology, and technological processing remains intriguingly undisclosed [29]. Understanding the aging mechanism requires paying attention to the crosstalk between different pathways leading to the degradation of cellular homeostasis. Non-enzymatic glycosylation (glycation) is a spontaneous reaction among reducing sugars (such as glucose), proteins, lipids, or nucleic acids leading to the age-associated accumulation of advanced glycation end products (AGEs) [30]. Glycation of proteins occurs by a complex series of sequential and parallel PTM reactions called collectively the Maillard reaction named after the leading pioneer of glycation research, Louis Camille Maillard (1878-1936) [31]. This Millard process is a nonenzymatic reaction between ketones or aldehydes, the amino groups of proteins, lipids, and nucleic acids eventually leading to the appearance of AGEs [32]. The interaction of AGEs with their receptors (RAGEs, which is a multiligand cell surface protein from the immunoglobulin superfamily capable of interaction with various partners, such as AGEs, amphoterin, amyloid fibrils, and S100/calgranulins [33]) is implicated in factors enhancing promoting protein racemization and aggregation (such as oxidative stress [34] and phosphorylation [13]). AGEs were experimentally observed in the seen in the skin [21], heart [35], lung [36], brain [37], and alcohol-mediated tissue injury [38]. AGEs were linked to the pathogenesis of numerous autoimmune, metabolic, and neurological disorders $[39,40]$. They have been identified during the progression of various aging-related diseases, such as diabetes [41], cardiovascular complications [42], kidney malfunctions [43,44], liver disorders [45, 46], lung injury [36], osteoporosis [47], atherosclerosis [48], skin cell melanogenesis [49], cancer [50], alcohol- 
mediated tissue injury [36]. arthritis [51], lupus [52], macular degeneration, cataract [42], and various neurodegenerative diseases linked to the abnormal accumulation of aggregated proteins [53, - 55] (e.g., Alzheimer's disease [56, 57], Parkinson's disease [58], Huntington's disease [59], multiple sclerosis [60], and amyotrophic lateral sclerosis [61]).

\section{Conclusions}

Amino acid racemization and AGE protein formation represent convolution of multistep reactions involving reversible and irreversible modifications of protein-specific amino acids (AAs) [21, 30]. Being spontaneous, age-dependent PTM glycation and racemization target many proteins and peptides \{ including amyloid-beta (A- $\beta$ ) [62], collagen [63 - 67], and chaperone heat shock proteins (HSPs) [65]\} and different cell type (including neurons). In turn, age-related decreases in neurogenesis are the primary causal events contributing to the cognitive decline. The crosstalk between the different forms of spontaneous PTMs is evident in the amyloid aggregates, which are insoluble proteinaceous entities composed of linear unbranched fibrils formed from the misfolded proteins [68, 69].

Proteostasis is a dynamic ensemble of cellular processes and pathways dedicated to the regulation of a balanced and functional proteome. Among the principal constituents of proteostasis are the common cellular pathways for the degradation of misfolded proteins. An important site for the degradation of misfolded proteins and dysfunctional protein aggregates is the lysosomes. Misfolded proteins and protein aggregates are trafficked to lysosomes by the macro-autophagy mechanisms, chaperonemediated autophagy, and endocytosis [69]. In eukaryotic cell, many damaged, misfolded, or oxidized proteins may also be degraded via the ubiquitin proteasome system (UPS) that conducts the nonlysosomal degradation of such targets. However, the amyloids represents the class of misfolded proteins resistant to proteasomal degradation, in part, due to their modification via the spontaneous non-enzymatic reactions. The representative example is $\beta$-amyloid $(A \beta)$ peptides, which are the substrate for spontaneous non-enzymatic age-dependent PTMs, including glycation [70] and 
racemization $[13,14]$. It is in logical agreement with the facts that glycated $\mathrm{A} \beta$ exhibits prolonged halflife [71], time-dependent isomerization/racemization of several AAs residues [72], misfolding, aggregation [73], and neurotoxicity [74].

Finally, we want to emphasize the fact that practically all glycation-prone proteins contain racemization-prone AA residues, providing the ground for the interaction of two distinct spontaneous determinants of protein aging, thereby defining the link between metabolic and epigenetics pathways of aging [12, 66, $67-77]$.

\section{Afterword}

The accumulation of unfolded/misfolded proteins activate a series of cell-specific stress responses, including unfolded protein response (UPR) $[78,79]$. In neuronal cells, the aggregates of unfolded [80] and misfolded [81] proteins lead to re-establishing cell homeostasis, dysfunctions of subcellular organelles, neurodegeneration, and cell death [82]. The complex of aforementioned events is associate with multiple spontaneous reactions $[83,84]$. However, the specific role of non-enzymatic spontaneous PTMs in cellular stress pathways remain mostly unclear [85]. 
Fig. 1. Schematic representation of funnel-shaped energy landscapes (entropy as a function of Gibbs free energy) for A- $\beta$ folding (enzymatic, reversible, non-amyloidogenic PTMs, and aggregation (spontaneous, irreversible, amyloidogenic PTMs). Conformational space for enzymatic and spontaneous phase transitions of protein between distinct protein folding states.

ATP-fueled enzymatic PTMs of proteins drive their substrates out of the thermodynamic equilibrium (toward the metastable native state) [56]. Spontaneous nonenzymatic PTMs drive the entire population of proteins toward thermodynamic equilibrium (to un-native state).

The local minimums of Gibbs free energy (E min) in conformational space provide relative nonequilibrium (NE) stabilization of native proteins (physiological conditions) and irreversible stabilization for misfolded proteins [56]. For misfolded states of proteins, E min can be two distinct categories. The discriminant between them is the condition whether the corresponding local minimum (min) of free energy $\left(\mathrm{E}^{\mathrm{min}}\right)$ is above (I) or below (II) the $\mathrm{E}^{\mathrm{min}}$ of native (functional b or physiological) state. The first categories (I) (relative $\mathrm{E}^{\mathrm{min}}$ ) are characterized as reversible and dynamic (physiological), while the second (II) (absolute $\mathrm{E}^{\mathrm{min})}$ as irreversible, pathological.

a. The native state (NS) can contain several $\mathrm{E}^{\min }[73]$.

b Proteins kinetically trapped in the local $\mathrm{E}^{\mathrm{min}}$ have a prolonged lifetime which increases the probability of the spontaneous PTMs $[1,2,13,14]$

Fragments are adopted with the alterations from $[71,72,73]$. 




\section{Chaperones}

Against

Spontaneous

Conformations

Sub-structure of Un-Native State Amorphous Aggregate

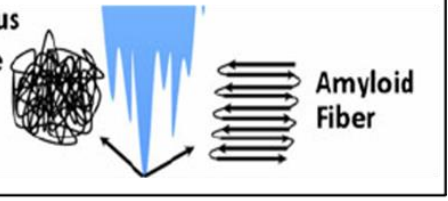


1 [Dyakin \& Lucas. 2017-A] Dyakin VV, and Lucas J. Non-Equilibrium Phase Transition in Biochemical Systems: Chain of Chirality Transfer as Determinant of Brain Functional Laterality Relevance to Alzheimer Disease and Cognitive Psychology. Poster (AAIC -2017) Title: Breaking the Chirality Silence: Search for New Generation of the Biomarkers. Protein Aggregation in Alzheimer's, Parkinson's, and Huntington's Diseases. The Journal of the Alzheimer's Association. 2017. 13:7. Supplement, P1498. Doi.org/10.1016/j.jalz.2017.07.595.

2. [Dyakin et al. 2017-B] Dyakin, V.V.; Justin Lucas, J.; Dyakina-Fagnano, N.V.; Eva V. Posner, E.V. Vadasz, C. The Chain of Chirality Transfer as Determinant of Brain Functional Laterality. Breaking the Chirality Silence: Search for New Generation of Biomarkers; Relevance to Neurodegenerative Diseases, Cognitive Psychology, and Nutrition Science. Neurology and Neuroscience Research. 2017;1(1):2, doi: 10.24983/scitemed.nnr.2017.00028

3 [Tamada. 2019] Tamada, A. Review. Chiral Neuronal Motility: The Missing Link between Molecular Chirality and Brain Asymmetry. Symmetry. 2019, 11(1), 102, doi.org/10.3390/sym11010102

4 [Zhavoronkov et al. 2019] Zhavoronkov, A.; Mamoshina, P.; Vanhaelen, Q.; Scheibye-Knudsen, M.; Moskalev, A.; Aliper, A. Review. Artificial intelligence for aging and longevity research: Recent advances and perspectives. Ageing Research Rev. 2019, 49, 49-66, doi.org/10.1016/j.arr.2018.11.003 5 [Ferrucci et al. 2018] Ferrucci, L.; Levine, M.; Kuo, P.L.; and Simonsick, E.M. Time and the Metrics of Aging. Circ Res. 2018, 123(7): 740-744, doi: 10.1161/CIRCRESAHA.118.312816

6 [Nikoletopou et al. 2014] Nikoletopou, V.; Kyriakakis, E.; Tavernarakis, N. Review. Cellular and molecular longevity pathways: the old and the new. Trends in Endocrinology \& Metabolism. 2014, 25(4), 212-223, doi.org/10.1016/j.tem.2013.12.003 
7 [Marchionni et al. 2020] Marchionni S.; Sell C. Lorenzini ADevelopment and Longevity: Cellular and Molecular Determinants - A Mini-Review. Gerontology. Regenerative Section. 2020, 66(3), 223230, doi.org/10.1159/000505327

8 [McColl et al. 2010] McColl, G. at al. Insulin-like signaling determines survival during stress via posttranscriptional mechanisms in C. elegans. Cell Metab. 2010, 12, 260-272, doi:10.1016/j.cmet.2010.08.004

9 [Hansen et al.2018] Hansen, M.; Rubinsztein, D.C. \& Walker, D.W. Autophagy as a promoter of longevity: insights from model organisms. Nat Rev Mol Cell Biol. 2018, 19, 579-593, doi.org/10.1038/s41580-018-0033-y

10 [Timmons et al. 2019] Timmons, J.A.; Volmar, C.H.; Crossland, H.; Phillips, B.E.; Sood, S.; Janczura, KJ.; Törmäkangas, T.; Kujala, U.M.; et al. Longevity-related molecular pathways are subject to midlife "switch" in humans. Agein Cell. 2019, 18(4), e12970, doi.org/10.1111/acel.12970

11 [Sleiman et al. 2020] Sleiman, M.B.; Jha, P.; Houtkooper, R.; Williams, R.W.; Wang, X. and Auwerx, J. The Gene-Regulatory Footprint of Aging Highlights Conserved Central Regulators. Cell Reports. 2020, 32(13). Doi.org/10.1016/j.celrep.2020.108203

12 [Saul, D. and Kosinsky. 2021] Saul, D. and Kosinsky, R.L. Epigenetics of Aging and AgingAssociated Diseases. Int. J. Mol. Sci. 2021, 22(1), 401, Doi.org/10.3390/ijms22010401

13 [Dyakin et al. 2020] Dyakin, V.V.; Thomas M. Wisniewski. T.W. and Abel Lajtha, A. Chiral Interface of Amyloid Beta (A $\beta$ ): Relevance to Protein Aging, Aggregation and Neurodegeneration. Symmetry 2020, 12(4), 585; doi.org/10.3390/sym12040585

14 [Dyakin et al. 2021] Dyakin, V.V.; Wisniewski, T.M. and Lajtha, A. Racemization in PostTranslational Modifications - Relevance to Protein Aging, Aggregation and Neurodegeneration: Tip of the Iceberg. Symmetry 2021, 13(3), 455, doi.org/10.3390/sym13030455 
15 [Meissner \& Ritz-Timme. 2010] Meissner, C. and Ritz-Timme, S. Molecular pathology and age estimation. Forensic Sci Int. 2010, 203(1-3):34-43, doi: 10.1016/j.forsciint.2010.07.010.

16 [Mayne et al. 2019] Mayne, B., Berry, O., Davies, C. et al. A genomic predictor of lifespan in vertebrates. Sci Rep. 2019, 17866, doi.org/10.1038/s41598-019-54447-w

17 [Yang et al. 2015] Yang, W.H.; Aziz, P.V.; Heithoff, D.M.; Mahan, M.J.; Smith, J.W. and Martha, J.D. An intrinsic mechanism of secreted protein aging and turnover. PNAS USA. 2015, 112(44): 13657-13662, doi: 10.1073/pnas.1515464112

18 [Paskal et al. 2013] Pascal, R.; Pross, A.; Sutherland, J.D. Towards an evolutionary theory of the origin of life based on kinetics and thermodynamics. Open Biol. 2013, 3(11), 30156, doi:

10.1098/rsob.130156

19 [Gaar et al. 2020] Gaar, J.; Naffa, R. and Brimble, M. Enzymatic and non-enzymatic crosslinks found in collagen and elastin and their chemical synthesis. Organic Chemistry Front. 2020, 7, 27992814, doi.org/10.1039/D0QO00624F

20 [McCudden \& Kraus. 2006] McCudden, C.R. and Kraus, V.B. Biochemistry of amino acid racemization and clinical application to musculoskeletal disease. Clin Biochem. 2006, 39(12), 11121130, doi: 10.1016/j.clinbiochem.2006.07.009.

21 [Gkogkolou \& Böhm. 2012] Gkogkolou P. and Böhm, M. Advanced glycation end products. Key players in skin aging? Dermatoendocrinol. 2012, 4(3): 259-270, doi: 10.4161/derm.22028

22 [Keller et al. 2015] Keller M.A.; Piedrafita, G.; Ralser, M. The widespread role of non-enzymatic reactions in cellular metabolism. Current Opinion in Biotechnology. 2015, 34, 153-161. doi: 10.1016/j.copbio.2014.12.020 
23 [Truscott et al. 2016] Roger J.W. Truscott, Kevin L. Schey, and Michael G. Friedrich. Old Proteins in Man: a Field in its Infancy. Trends Biochem Sci. 2016 Aug; 41(8): 654-664, doi:

10.1016/j.tibs.2016.06.004

24 [Federoff 1993] Federoff HJ, Lawrence D, Brownlee M. Non enzymatic glycosylation of laminin and the laminin peptide CIKVAVS inhibits neurite outgrowth. Diabetes 1993, 42, 509-13, doi: 10.2337/diab.42.4.509

25 [Brownlee. 1995] Brownlee, M. Advanced Protein Glycosylation in Diabetes and Aging. Annu. Rev. Med. 1995, 46, 223-34. doi.org/10.1146/annurev.med.46.1.223 Michael Brownlee

26 [Paton et al. 2021] Beatrix Paton, Manuel Suarez, Pol Herrero, and Núria Canela. Review.

Glycosylation Biomarkers Associated with Age-Related Diseases and Current Methods for Glycan Analysis. Int. J. Mol. Sci. 2021, 22, 5788, doi.org/10.3390/ijms22115788

27 [Purich. 2010] Book by Daniel L. Purich. Enzyme Kinetics: Catalysis and Control: A Reference of Theory and Best -Practoce Methods. Acad. Press. Elsevier. First Edition. 2010.

28 [Krisko \& Radman. 2019] Anita Krisko and Miroslav Radman. Protein damage, ageing and agerelated diseases. Open Biol. 2019. 9:3:180249. Doi: 10.1098/rsob.180249.

29 [Mittal \& Rath. 2020]. Mittal A, and Rath P.C. Protein Structure and Function in Aging and AgeRelated Diseases. Chapter in book: Models, Molecules and Mechanisms in Biogerontology, Cellular Processes. Metabolism and Diseases 2020. Pg. 3-26. Doi: 10.1007/978-981-32-9005-1_1

30 [Rabbani \& Thornalley. 2012] Rabbani, N., Thornalley, P.J. Glycation research in amino acids: a place to call home. Amino Acids 2012, 42, 1087-1096, doi: 10.1007/s00726-010-0782-1

31 [Younus \& Anwar. 2016] Younus, H. and Anwar, S. Prevention of non-enzymatic glycosylation (glycation): Implication in the treatment of diabetic complication. Int J Health Sci (Qassim). 2016, 10(2): 261-277. 
32 [Dyer et al 1991] Dyer, D.G.; Blackledge, J.A.; Thorpe, S.R.; Baynes, J.W. Formation of pentosidine during nonenzymatic browning of proteins by glucose. Identification of glucose and other carbohydrates as possible precursors of pentosidine in vivo. J Biol Chem. 1991, 266(18), 11654-60. PMID: 1904867

33 [Stern et al. 2002] Stern, D.; Yan, S.D.; Yan, S.F.; Schmidt, A.M. Receptor for advanced glycation endproducts: a multiligand receptor magnifying cell stress in diverse pathologic settings. Adv. Drug Deliv. Rev. 2002, 54(12), 615-265. doi: 10.1016/s0169-409x(02)00160-6. PMID: 12453678 34 [Nowotny et al. 2015] Nowotny, K.; Jung, T.; Höhn, A.; Weber, D.; Grune, T. Advanced glycation end products and oxidative stress in type 2 diabetes mellitus Biomolecules. 2015, 5(1):194-222. doi: 10.3390/biom5010194.

35 [Schröter \& Höhn. 2018] Schröter, D. and Höhn, A. Review. Role of Advanced Glycation End Products in Carcinogenesis and their Therapeutic Implications. Curr Pharm Des. 2018, 24(44):52455251, doi: 10.2174/1381612825666190130145549.

36 [Uchida et al. 2006] Uchida, T.; Shirasawa, M, Ware, L.B.; Kojima, K.; Hata, Y.; Makita, K.; Mednick, G.; Matthay, Z.A.; and Matthay, M.A. Receptor for Advanced Glycation End-Products Is a Marker of Type I Cell Injury in Acute Lung Injury. Am J Respir Crit Care Med. 2006, 173(9), 10081015, doi: 10.1164/rccm.200509-14770C

37 [Dobi et al. 2021] Dobi, A.; Rosanaly, S.; Devin, A.; Baret, P.; Meilhac., O.; G. JeanHarry, G.J.; d'Hellencourt, C.L.; Rondeau, P. Advanced glycation end-products disrupt brain microvascular endothelial cell barrier: The role of mitochondria and oxidative stress. Microvascular Res, 2021, 133(104098), doi.org/10.1016/j.mvr.2020.104098

38 [Rungratanawanich et al. 2021] Rungratanawanich, W., Qu, Y., Wang, X. et al. Advanced glycation end products (AGEs) and other adducts in aging-related diseases and alcohol-mediated tissue injury. Exp Mol Med. 2021, 53, 168-188, oi.org/10.1038/s12276-021-00561-7 
39 [Lushington \& Barnes, 2019] Lushington, G.H. and Barnes, A.C. Protein Glycation: An Old Villain is Shedding Secrets. Comb. Chem. High Throughput Screen. 2019, 2(6), 62-369, doi:10.2174/1386207322666190704094356. PMID: 31272349

40 [Kuzan. 2021] Kuzan, A. Toxicity of advanced glycation end products (Review). Biomed. Rep. 2021, 14(5), 46, doi: 10.3892/br.2021.1422. PMID: 33786175

41 [Yang et al. 2019] Yang, P.; Feng, J.; Peng, Q.; Liu, X.; and Fan, Z. Review.Advanced Glycation End Products: Potential Mechanism and Therapeutic Target in Cardiovascular Complications under Diabetes. Oxidative Medicine and cellular Longevity. 2019, 2019(9570616), doi.org/10.1155/2019/9570616 42 [Bejarano \& Taylor,] Bejarano, E. and Taylor, A. Review Too sweet: Problems of protein glycation in the eye. Exp Eye Res. 2019, 78, 255-262, doi: 10.1016/j.exer.2018.08.017. PMID: 30145354 43 [Yubero-Serrano \& Pérez-Martínez. 2020] Yubero-Serrano E.M. and Pérez-Martínez, P. Advanced glycation end products and their involvement in cardiovascular disease. Angiology. 2020, 71(8), 698-700, doi: 10.1177/0003319720916301

44 [Bohlender et al. 2005] Bohlender, J.M.; Franke, S.; Stein, G.; Gunter Wolf, G, Review. Advanced glycation end products and the kidney. Am J Physiol Renal Physiol. 2005, 289(4), F645-F659. doi: 10.1152/ajprenal.00398.2004.

45 [Byun et al. 2017] Byun, K. et al. Advanced glycation end-products produced systemically and by macrophages: a common contributor to inflammation and degenerative diseases. Pharmacol.

Therapeutics 177, 44-55 (2017).

46 [Abate et al. 2017] Abate, G., Marziano, M., Rungratanawanich, W., Memo, M. \& Uberti, D. Nutrition and AGE-ing: focusing on Alzheimer's disease. Oxid. Med. Cell. Longev. 2017, 2017(7039816), doi: 10.1155/2017/7039816.2017, 1-10 (2017) 
47 [Yamagishi. 2011] Yamagishi S. Role of advanced glycation end products (AGEs) in osteoporosis in diabetes. Curr Drug Targets. 2011, 12(14):2096-20102, doi: 10.2174/138945011798829456 48 [Vlassara. 1996] Vlassara, H. Advanced Glycation End-products and Atherosclerosis. Annals of Medicine. 1996. 28(5), 419-426, doi.org/10.3109/07853899608999102

49 [Lee et al. 2016] Lee, E., Kim, J. \& Oh, S. Advanced glycation end products (AGEs) promote melanogenesis through receptor for AGEs. Sci Rep 2016, 6(27848), doi.org/10.1038/srep27848 50 [Rehman et al. 2020] Rehman, S.; Aatif, M.; Rafi, Z.; Khan, M.Y.; Shahab, U.; Ahmad, S.; Farhan, M. Effect of non-enzymatic glycosylation in the epigenetics of cancer. Seminars in Cancer Biol. 2020, doi.org/10.1016/j.semcancer.2020.11.019

51 [Chuah et al. 2013] Chuah, Y.K.; Basir, R.; Talib, H.; Tie, T.H. and Nordin. N. Receptor for Advanced Glycation End Products and Its Involvement in Inflammatory Diseases. Int. J. of Infl. 2013, 2013(403460), doi.org/10.1155/2013/403460

52 [Nowak et al. 2020] Nowak, A.; Przywara-Chowaniec, B.; Krystyna Tyrpień-Golder, K.; Ewa Nowalany-Kozielska, E. Systemic lupus erythematosus and glycation process Cent Eur J Immunol. 2020; 45(1): 93-98, doi: 10.5114/ceji.2018.77875 PMID: 32425686

53 [Li et al. 2012] Li, J.; Liu, D.; Sun, L.; Lu, Y.; Zhang, Z. Advanced glycation end products and neurodegenerative diseases: mechanisms and perspective. Neurol Sci. 2012, 317(1-2),1-5. doi: 10.1016/j.jns.2012.02.018.

54 [Kikuchi et al. 2003] Kikuchi, S.; Shinpo, K.; Takeuchi, M.; Yamagishi, S.; Makita, Z.; Sasaki, N.; Tashiro, K. Glycation--a sweet tempter for neuronal death. Brain Res Brain Res Rev. 2003, 41(2-3), 306-23. doi: 10.1016/s0165-0173(02)00273-4. PMID: 12663085 55 [Salahuddin 2014] Salahuddin, P.; Rabbani, G.; Khan, R.H. The role of advanced glycation end products in various types of neurodegenerative disease: a therapeutic approach. Cell Mol Biol Lett. 2014, 19(3), 407-437, doi: 10.2478/s11658-014-0205-5. PMID: 25141979 
56 [Takeuchi et al. 2004=] Takeuchi, M.; Kikuchi, S.; Sasaki, N.; Suzuki, T.; Watai, T.; Iwaki, M.;

Bucala, R.; Yamagishi, S. Review. Involvement of advanced glycation end-products (AGEs) in Alzheimer's disease. Curr Alzheimer Res. 2004, 1(1),39-46, doi: 10.2174/1567205043480582. PMID: 15975084

57 [Prasad. 2019] Prasad K. AGE-RAGE stress: a changing landscape in pathology and treatment of Alzheimer's disease. Molecular and Cellular Biochem. 2019, 459(1-2), 95-112, doi: 10.1007/s11010019-03553-4 PMID: 31079281

58 [Guerrero et al. 2012] Guerrero E, Vasudevaraju P, Hegde ML, Britton GB, Rao KS.

Recent advances in $\alpha$-synuclein functions, advanced glycation, and toxicity: implications for Parkinson's disease. Molecular Neurobiol. 2012, 47(2),525-536, doi:10.1007/s12035-012-8328-z. PMID: 22923367

59 [Brás et al. 2018] Brás IC, König A, Outeiro TF. Glycation in Huntington's Disease: A Possible Modifier and Target for Intervention. Journal of Huntington's Dis. 2018, 8(3),245-256, doi: 10.3233/jhd-190366. PMID: 31322580

60 [Wetzels et al. 2017] Wetzels, S.; Wouters, K.; Schalkwijk, C.G.; Vanmierlo, T.; Jerome J A Hendriks, J.J.A. Methylglyoxal-Derived Advanced Glycation Endproducts in Multiple Sclerosis. Int J Mol Sci. 2017, 18(2), 421, doi: 10.3390/ijms18020421. PMID: 28212304

61 [Kato] Kato, S.; Nakashima, K.; Horiuchi, S.; Nagai, R.; Cleveland, D.W.; Liu, J.; Hirano, A.; Takikawa, M.; Kato, M.; Nakano, I.; Sakoda, S.; Asayama, K.; Ohama, E. Review. Formation of advanced glycation end-product-modified superoxide dismutase-1 (SOD1) is one of the mechanisms responsible for inclusions common to familial amyotrophic lateral sclerosis patients with SOD1 gene mutation, and transgenic mice expressing human SOD1 gene mutation. Neuropathology. 2001, 21(1), 67-81, doi: 10.1046/j.1440-1789.2001.00359.x 
62 [Miranda et al. 2016] Miranda, H.V.; El-Agnaf, O.M.A.; Outeiro, T.F. Review. Glycation in Parkinson's disease and Alzheimer's disease. Mov Disord. 2016, 31(6):782-790, doi:

$10.1002 / \mathrm{mds} .26566$

63 [Paul \& Bailey. 1996] Paul RG, Bailey AJ. Glycation of collagen: the basis of its central role in the late complications of ageing and diabetes. Int J Biochem Cell Biol. 1996, 28, 1297-310. doi:

10.1016/S1357-2725(96)00079-9ferences

64 [Fessel et al. 2014] Fessel, G.; Li, Y.; Diederich, V.; Guizar-Sicairos, M.; Schneider, P.; Sell, D.R.; Monnier, V.M.; Snedeker, J.G. Advanced Glycation End-Products Reduce Collagen Molecular Sliding to Affect Collagen Fibril Damage Mechanisms but Not Stiffness. PLOS ONE. 2014. (11): e110948, doi.org/10.1371/journal.pone.0110948

65 [Verzijl et al. 2000] Verzijl, N.; DeGroot, J.; Shorpe, S.R.; Bank, R.A.; Shaw, J.N.; Lyons, T.J.; Bijlsma, J.W.J; Lafeber, F.PJG.; Baynes, J.W.; TeKoppele, J.M. Effect of Collagen Turnover on the Accumulation of Advanced Glycation End Products. JBC. J. of Biol. Chem. 2000, 275(50), P3902739031, doi.org/10.1074/jbc.M006700200

66 [Ohashi et al. 2004] Ohashi, S.; Abe, H.; Takahashi, T.; Yamamoto, Y.; Takeuchi, M.; Arai, H.;

Nagata, K.; Kita, T.; Okamoto, H.; Yamamoto, H.; Doi, T. Advanced glycation end products increase collagen-specific chaperone protein in mouse diabetic nephropathy. J Biol Chem. 2004, 7;279(19):19816-23, doi: 10.1074/jbc.M310428200

67 [Zheng et al. 2020] Zheng, Q., Maksimovic, I., Upad, A. et al. Non-enzymatic covalent modifications: a new link between metabolism and epigenetics. Protein Cell 2020, 11, 401-416, doi: 10.1007/s13238-020-00722-w

68 [Rambaran \& Serpell. 2008] Rambaran R.N. and Serpell L.C. Amyloid fibrils. Abnormal protein assembly. Prion. 2008, 2(3): 112-117, doi: 10.4161/pri.2.3.7488 
69 [Jackson \& Eric. 2016] Jackson M.P and Eric W. Hewitt, E.W. Monitoring Editor: Patricija van Oosten-Hawle. Cellular proteostasis: degradation of misfolded proteins by lysosomes. Essays Biochem. 2016, 60(2), 173-180, doi: 10.1042/EBC20160005

70 [Li et al. 2013] Li, X-H.; Du, L-L.; Cheng, X-S.; Jiang, X.; Zhang, Y.; Lv, B-L.; Liu, R.; Wang, JZ.; Zhou. X-W. Glycation exacerbates the neuronal toxicity of $\beta$-amyloid. Cell Death Dis. 2013, 4(6):e673, doi: 10.1038/cddis.2013.180

71 [Iannuzzi et al. 2014] Iannuzzi, C.; Irace, G.; and Sirangelo, I. Review. Differential effects of glycation on protein aggregation and amyloid formation. Front. Mol. Biosci. 2014, doi.org/10.3389/fmolb.2014.00009

72 [Vitek et al. 1994] Vitek, M.P.; Bhattacharya, K.; Glendening, J.M.; Stopat, E.; Vlassara, H.; Bucala, R.; Manogue, K.; and Cerami, A. Advanced glycation end products contribute to amyloidosis in Alzheimer disease. PNAS USA 1994, 91, 4766-4770, doi.org/10.1073/pnas.91.11.4766 73 [Emendato et al. 2018] Emendato, A.; Milordini, G.; Zacco, E.; Sicorello, A.; Piaz, F.G.; Remo Guerrini, R.; Thorogate, R.; Picone, D.; Pastore, A. Glycation affects fibril formation of A $\beta$ peptides. Journal of Biolog ical Chemistry. JBC. 2018, 293(34), 13100-1311, doi.org/10.1074/jbc.RA118.002275

74 [Ko et al. 2015] Shun-Yao Ko, Hshin-An Ko, Kuo-Hsiung Chu, Tzong-Ming Shieh, Tzong-Cherng Chi, Hong-I Chen, Weng-Cheng Chang, Shu-Shing Chang. The Possible Mechanism of Advanced Glycation End Products (AGEs) for Alzheimer's Disease. PLoS One. 2015, 10(11):e0143345, doi: 10.1371/journal.pone.0143345.

75 [Almeida and Brito. 2020] Almeida. Z.L. and Brito. R.M.M. Botond Penke, Academic Editor. Structure and Aggregation Mechanisms in Amyloids. Molecules. 2020, 25(5), 1195, doi: 10.3390/molecules25051195 
76 [Goloubinoff et al. 2018] Goloubinoff, P.; Sassi, A.S.; Fauvet, B.; Barducci, A.; Paolo De Los Rios. Molecular chaperones inject energy from ATP hydrolysis into the non-equilibrium stabilization of native proteins. Nature Chem. Biol. 2018, 14(4), 388-395. doi: 10.1038/s41589-018-0013-8 77 [Cordeiro et al. 2014] Cordeiro, Y.; Macedo, B.; Silva, J.S.; Gomes, M.P.B. Pathological implications of nucleic acid interactions with proteins associated with neurodegenerative diseases. Biophysical Rev. 2014, 6(1), doi: 10.1007/s12551-013-0132-0

78 [Reynaud. 2010] Reynaud, E. Protein Misfolding and Degenerative Diseases. Nature Education 2010, 3(9), 28

79 [Niu et al. 2017] Niu, M.; Dai, X.; Zou, W.; Yu, X.; Teng, W.; Chen, Q.; Sun, X.; Yu, W.; Ma, H. and Liu, P. Autophagy, endoplasmic reticulum stress and the unfolded protein response in intracerebral hemorrhage. Translational Neuroscience. 2017, 8(1), doi.org/10.1515/tnsci-2017-0008

80 [March et al. 2021] March, D.; Bianco, V.; and Franzese, G. Protein unfolding and aggregation near a hydrophobic interface. Polymers (MDPI) 2021, 13(156), doi.org/10.3390/polym13010156

81 [Ashraf et al 2014] Ashraf, G.M.; Nigel H. Greig, N.H.; Khan, T.A.; Hassan, I.; Tabrez, S.; Shakil, S. et al. Protein misfolding and aggregation in Alzheimer's disease and Type 2 Diabetes Mellitus. CNS Neurol Disord. Drug Targets. 2014; 13(7): 1280-1293. doi: 62 $10.2174 / 1871527313666140917095514$

82 [Cao \& Kaufman. 2012] Cao, S.S. and Randal J. Kaufman. Current Biology. Unfolded protein response. Current Biology 2012, 22(16), R622-R626, doi.org/10.1016/j.cub.2012.07.004 83 [Uversky. 2008] Uversky, V. Amyloidogenesis of Natively Unfolded Proteins. Curr. Alzheimer Res. 2008, 5(3), 260-287, doi: 10.2174/156720508784533312

84 [Lindholm et al. 2017] Dan Lindholm, D.; Korhonen, L.; Eriksson, O.; Kõks, S. Recent Insights into the Role of Unfolded Protein Response in ER Stress in Health and Disease. Frontiers in Cell and Developmental Biology 2017 1(5), doi: 10.3389/fcell.2017.00048 
85 [Karumanchi et al. 2015] Karumanchi, D.K.; Karunaratne, N.; Lurio, L.; Dillon, J.P.; Gaillard, E.R. Non-enzymatic glycation of $\alpha$-crystallin as an in vitro model for aging, diabetes and degenerative diseases. Amino Acids. 2015, 47(12):2601-8, doi: 10.1007/s00726-015-2052-8 